\title{
Corrigendum: Global Text Mining and Development of Pharmacogenomic Knowledge Resource for Precision Medicine
}

\begin{abstract}
Debleena Guin ${ }^{1,2}$, Jyoti Rani ${ }^{3,4}$, Priyanka Singh ${ }^{1,5}$, Sandeep Grover ${ }^{6}$, Shivangi Bora ${ }^{1,2}$, Puneet Talwar ${ }^{7}$, Muthusamy Karthikeyan ${ }^{8}$, K. Satyamoorthy ${ }^{9}$, C. Adithan ${ }^{10}$, S. Ramachandran ${ }^{4,5}$, Luciano Saso ${ }^{11}$, Yasha Hasija ${ }^{2}$ and Ritushree Kukreti ${ }^{1,5 *}$

${ }^{1}$ Genomics and Molecular Medicine Unit, Council of Scientific and Industrial Research (CSIR)-Institute of Genomics and Integrative Biology (IGIB), New Delhi, India, ${ }^{2}$ Department of Biotechnology, Delhi Technological University, Delhi, India, ${ }^{3}$ Department of Biomedical Sciences, Acharya Narayan Dev College, University of Delhi, New Delhi, India, ${ }^{4} G N$ Ramachandran Knowledge Centre, Council of Scientific and Industrial Research (CSIR)-Institute of Genomics and Integrative Biology (IGIB), New Delhi, India, ${ }^{5}$ Academy of Scientific \& Innovative Research (AcSIR), New Delhi, India, ${ }^{6}$ Institute of Medical Biometry and Statistics, University of Lübeck University Medical Center Schleswig-Holstein - Campus Lübeck, Lübeck, Germany, ${ }^{7}$ Institute of Human Behaviour and Allied Sciences, Delhi, India, ${ }^{8}$ Department of Bioinformatics, Alagappa University, Karaikudi, India, ${ }^{9}$ School of Life Sciences, Manipal University, Manipal, India, ${ }^{10}$ Central Inter-Disciplinary Research Facility (CIDRF), Pondicherry, India, ${ }^{11}$ Department of Physiology and Pharmacology "Vittorio Erspamer," Sapienza University of Rome, Rome, Italy
\end{abstract}

Keywords: text mining, precision medicine, disease-drug-gene-mutation relationship, pharmacogenomic markers, pharmacogenomic knowledgebase

\section{A corrigendum on}

Global Text Mining and Development of Pharmacogenomic Knowledge Resource for Precision Medicine

by Guin, D., Rani, J., Singh, P., Grover, S., Bora, S., Talwar, P., et al. (2019). Front. Pharmacol. 10:839. doi: 10.3389/fphar.2019.00839

In the original article, Supplementary Table 11 is missing, as published. Supplementary Table 11 is mentioned in the article text in Discussion section, para 4, but it is missing from the Supplementary file. Also, Supplementary Table 12 mentioned under section 'A Resource for Pharmacogenomic Evaluation' in the original article should be Supplementary Table 11.

The authors apologize for this error and state that this does not change the scientific conclusions of the article in any way. The original article has been updated.

\section{SUPPLEMENTARY MATERIAL}

The Supplementary Material for this article can be found online at: https://www.frontiersin.org/ articles/10.3389/fphar.2020.614445/full\#supplementary-material

Copyright ( 2020 Guin, Rani, Singh, Grover, Bora, Talwar, Muthusamy, Satyamoorthy, Adithan, Ramachandran, Saso, Hasija and Kukreti. This is an open-access article distributed under the terms of the Creative Commons Attribution License (CC BY). The use, distribution or reproduction in other forums is permitted, provided the original author(s) and the copyright owner(s) are credited and that the original publication in this journal is cited, in accordance with accepted academic practice. No use, distribution or reproduction is permitted which does not comply with these terms. 